\title{
Can concussion constrain the Caped Crusader?
}

\author{
E Paul Zehr, 1,2,3,4,5,6,7 Bruce Wright ${ }^{2,3,4,8}$
}

\section{INTRODUCTION}

A popular 'Snickers' commercial from 1996 shows a hard collision in American football that leaves a player supine on the turf. This is followed by an exchange between the sideline coach and player: Coach: "Look around-where are you?" Player (slight furrow of brow while thinking): "In New York."

Coach: "Who am I?"

Player (smiling): "Coach!"

Coach: "Who are you?"

Player (looking very serious and replying in a low tone): “...I'm Batman..."

The message of the Snickers commercial is that when concussed, a person might believe that they are actually Batman. We are wondering whether Batman himself has ever been concussed and, if so, when asked by Alfred if he knew who he was, might Bruce Wayne answer "an NFL quarterback?". This paper looks for any evidence of concussion in the big screen representation of Batman that would suggest he might give that type of answer.

While historically there have been numerous definitions of 'concussion', the most commonly accepted medical diagnostic definition is that derived from the 4th International Conference on Concussion in Sport held in 2012 in Zurich: "Concussion is a brain injury and is defined as a complex pathophysiological process affecting the brain, induced by biomechanical forces". ${ }^{1}$

\footnotetext{
${ }^{1}$ Rehabilitation Neuroscience Laboratory, University of Victoria, Victoria, British Columbia, Canada; ${ }^{2}$ Division of Medical Sciences, University of Victoria, Victoria, British Columbia, Canada; ${ }^{3}$ sland Medical Program, University of Victoria, Victoria, British Columbia, Canada; ${ }^{4}$ Centre for Biomedical Research, University of Victoria, Victoria, British Columbia, Canada; ${ }^{5}$ Exercise Science, Physical and Health Education, University of Victoria, Victoria, British Columbia, Canada; ${ }^{6}$ Division of Neurology, Department of Medicine, Faculty of Medicine, University of British Columbia, Victoria, British Columbia, Canada; ${ }^{7}$ Human Discovery Science, International Collaboration on Repair Discoveries (ICORD), Vancouver, British Columbia, Canada; ${ }^{8}$ Department of Family Medicine, Faculty of Medicine, University of British Columbia, Vancouver, British Columbia, Canada
}

Correspondence to Dr E Paul Zehr, Centre for Biomedical Research, University of Victoria, Petch 041f, Victoria, BC V8P 5C2, Canada; pzehr@uvic.ca
Concussion has been a pernicious, pervasive and under-reported health issue in sport and in public life. ${ }^{2} 3$ Where available, data on the prevalence and incidence of concussion show an overall injury rate of 2.5 per 10000 athletic exposures ${ }^{4}$ and statistics from the NCAA show concussion rates increasing by $7 \%$ over a 16 year study period. ${ }^{5}$ Guzkiewicz et al reported a prevalence of $\sim 5.5 \%$ for both Division III and High School Football and that once a player had experienced a concussion, the likelihood of a second concussion that season was tripled. ${ }^{6}$ Concussion and the long-term risks of repeated head trauma have been afforded a huge spotlight given the extreme popularity of the NFL and the concussion crisis recently exposed there. ${ }^{7}$

The symptoms of concussion are characterised by the "rapid onset of shortlived impairment of neurological function that resolves spontaneously...symptoms and signs may evolve over a number of minutes to hours". ${ }^{1}$ These can be grouped into five main areas assessed during clinical diagnosis: (1) somatic, physical and cognitive symptoms (headache, feeling slowed down, poor balance, etc); (2) physical signs (loss of consciousness); (3) changes in behaviour; (4) impaired cognition and (5) disturbed sleep. Common symptoms include dizziness, headache and disorientation but effective and reliable diagnosis of concussion is hampered by the typical lack of abnormalities found in neuroimaging. ${ }^{1}$

Beyond sport, other avenues of popular culture show significant potential for bodily and brain trauma-namely that of superheroes. The issue of concussion has been explicitly addressed in popular culture books aimed at adults ${ }^{8-10}$ and teens. ${ }^{11} 12$ Scenarios likely to result in concussion appear regularly in superhero comics, graphic novels and movies where injuries resulting from a mechanism involving a 'direct blow to the head, face, neck or elsewhere on the body with an 'impulsive' force transmitted to the head' are common occurrence in daily superhero life. ${ }^{1}$

Iron Man has been on the scene since his debut in 'Tales of Suspense' \#39 from March of 1963. In the 2008 Marvel Studios 'Iron Man' movie, during his climactic battle with Iron Monger, Tony Stark (played to excellent effect by Robert Downey Jr.) received seven concussive events within the span of 1-min. These included slamming into a car, being pummelled by Iron Monger, being slammed into a bus and an explosive blast.

Despite a large number of exposures shown in the comics, the symptoms of concussion are rarely discussed. An early exception is that shown in the panel below, taken from the 1975 story 'This one'll kill you Batman' (it did not, by the way) found in Batman \#260. Even so, the effects of postconcussive symptoms are downplayed and instead, the influence of a drug that was slipped into Batman's coffee is labelled as the culprit. We know that these injuries can seriously impact daily life but Batman does not display many (if any) of these symptoms (figure 1).

Compared with Iron Man, Batman is a true granddaddy dating all the way back to the 1930s. Batman, or 'The Bat-Man' as he was introduced, arrived on the comic book scene way back in 'Detective Comics' \#27 in May of 1939. His 'Batsuit', while offering protection of sorts, is certainly minimalist compared with the exoskeletal armour of Iron Man. Currently, there is considerable research evaluating the influence of protective equipment and whether or not they are actually that protective-helmets, mouth guards, scrum caps, neck bands. ${ }^{13} 14$

Clearly, many of these protective innovations are not present in Batman's 'cape and cowl'. Which raises the questionhow much concussion exposure has Batman actually had? If indeed the answer to the former is the probable one of ' $a$ lot', the subsequent question of does Batman show evidence of chronic traumatic encephalopathy (CTE) is one worth considering. These are the central questions of this paper.

\section{METHODS \\ Participants}

The sole participant studied was that of the DC Comics character of 'Batman' as portrayed on the 'big screen' by Lewis G Wilson (1943), Robert Lowrey (1949), Michael Keaton (1989 and 1992), Val Kilmer (1995), George Clooney (1997), Christian Bale $(2005,2008,2012)$ and Ben Affleck (2016). The complete list of films is found in table 1 .

\section{Main outcome measures}

Number and severity of potentially concussive events experienced by direct head trauma or bodily impact. Each possible incident was scored by: type of impact 


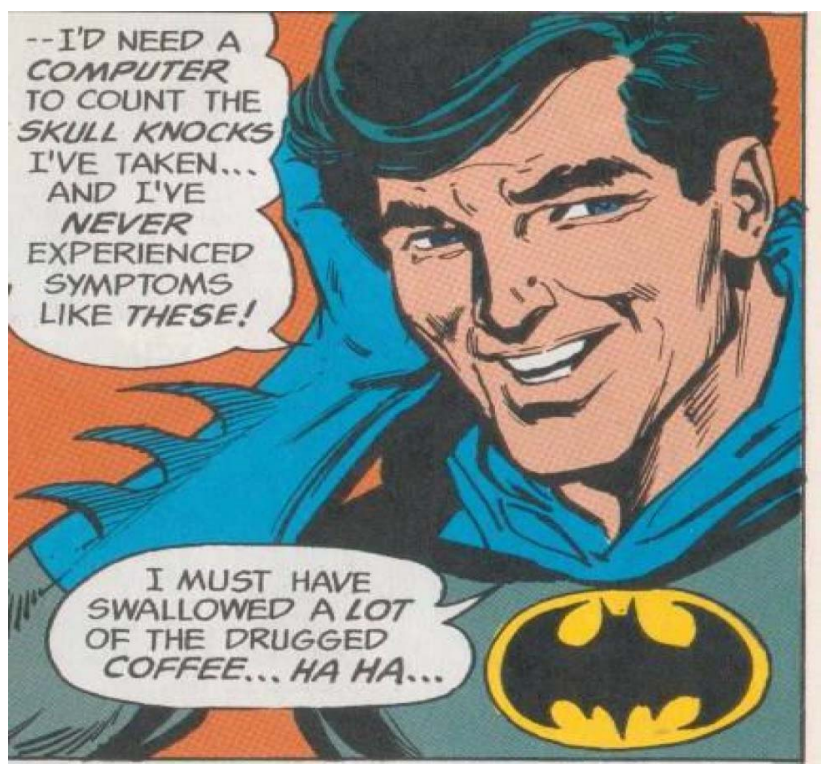

Figure 1 Batman partially admitting to concussion symptoms from Batman \#260 (1975). Batman (C) DC Comics.

Table 1

\begin{tabular}{|c|c|c|c|}
\hline Movie and run time & Actor & $\begin{array}{l}\text { Number of } \\
\text { events }\end{array}$ & Notables \\
\hline $\begin{array}{l}\text { Batman, the } 1943 \text { black-and-white } \\
\text { 15-chapter theatrical serial from } \\
\text { Columbia Pictures; } 260 \text { min }\end{array}$ & $\begin{array}{l}\text { Lewis G } \\
\text { Wilson }\end{array}$ & 43 & $\begin{array}{l}\text { Batman is not very skilled at fighting } \\
\text { and gets hit on the head/face often. }\end{array}$ \\
\hline $\begin{array}{l}\text { Batman and Robin, a 15-part serial } \\
\text { released in } 1949 \text { by Columbia Pictures; } \\
264 \mathrm{~min}\end{array}$ & $\begin{array}{l}\text { Robert } \\
\text { Lowrey }\end{array}$ & 19 & $\begin{array}{l}\text { Batman fighting improves and he } \\
\text { avoids many hits. }\end{array}$ \\
\hline $\begin{array}{l}\text { Batman, a } 1989 \text { Warner Brothers film } \\
\text { directed by Tim Burton; } 126 \text { min }\end{array}$ & $\begin{array}{l}\text { Michael } \\
\text { Keaton }\end{array}$ & 9 & $\begin{array}{l}\text { Batman, while moving stiffly, avoids } \\
\text { most hits. }\end{array}$ \\
\hline $\begin{array}{l}\text { Batman Returns, a } 1992 \text { Warner } \\
\text { Brothers film directed by Tim Burton; } \\
126 \mathrm{~min}\end{array}$ & $\begin{array}{l}\text { Michael } \\
\text { Keaton }\end{array}$ & 8 & $\begin{array}{l}\text { Batman avoids most blows from } \\
\text { opponents. }\end{array}$ \\
\hline $\begin{array}{l}\text { Batman Forever, a } 1995 \text { Warner } \\
\text { Brothers film directed by Joel } \\
\text { Schumacher; } 122 \mathrm{~min}\end{array}$ & Val Kilmer & 5 & \\
\hline $\begin{array}{l}\text { Batman and Robin, a } 1997 \text { Warner } \\
\text { Brothers film directed by Joel } \\
\text { Schumacher; } 125 \text { min }\end{array}$ & $\begin{array}{l}\text { George } \\
\text { Clooney }\end{array}$ & 6 & \\
\hline $\begin{array}{l}\text { Batman Begins, a } 2005 \text { Warner } \\
\text { Brothers film directed by Christopher } \\
\text { Nolan; } 140 \mathrm{~min}\end{array}$ & $\begin{array}{l}\text { Christian } \\
\text { Bale }\end{array}$ & 18 & $\begin{array}{l}\text { Batman's backstory is told in detail, } \\
\text { including exposure to trauma during } \\
\text { training. }\end{array}$ \\
\hline $\begin{array}{l}\text { The Dark Knight, a } 2008 \text { Warner } \\
\text { Brothers film directed by Christopher } \\
\text { Nolan; } 152 \text { min }\end{array}$ & $\begin{array}{l}\text { Christian } \\
\text { Bale }\end{array}$ & 14 & $\begin{array}{l}\text { The physical trauma of Batman's life is } \\
\text { shown for the 1st time. }\end{array}$ \\
\hline $\begin{array}{l}\text { The Dark Knight Rises, a } 2012 \text { Warner } \\
\text { Brothers film directed by Christopher } \\
\text { Nolan; } 165 \text { min }\end{array}$ & $\begin{array}{l}\text { Christian } \\
\text { Bale }\end{array}$ & 28 & $\begin{array}{l}\text { In } 3 \mathrm{~m} \text { of fighting Bane, Batman is } \\
\text { exposed to } 14 \text { potentially concussive } \\
\text { events. }\end{array}$ \\
\hline $\begin{array}{l}\text { Batman V Superman: Dawn of Justice, } \\
\text { a } 2016 \text { Warner Brothers film directed } \\
\text { by Zack Snyder, } 151 \text { min }\end{array}$ & $\begin{array}{l}\text { Ben } \\
\text { Affleck }\end{array}$ & 26 & $\begin{array}{l}\text { The scale of Batman's trauma reaches a } \\
\text { peak in the fight vs Superman, which } \\
\text { includes } 5 \text { events that would almost } \\
\text { certainly be fatal. }\end{array}$ \\
\hline Total=1631 $\mathrm{min}$ & & $\begin{array}{l}\text { Grand } \\
\text { total }=176\end{array}$ & \\
\hline
\end{tabular}

(fight, accident or collateral damage), source of impact (fist, foot, weapon, object, vehicle, building/ground), primary impact location (head, upper body, lower body, limbs), portrayed reaction (no effect, dazed, unconscious), likely involved either a direct impact to the face or head or overall impulsive body motion likely to impart significant interaction forces on the head and brain.

\section{RESULTS AND DISCUSSION}

Do Batman's activities expose him to potentially concussive events?

Although there are not any real data on the stresses and strains of nocturnal vigilante crime fighting as Batman in Gotham City, there are examples of real activities that provide real-life benchmarks for what would be entailed in the Dark Knight's crime-fighting escapades. Previously, one of us argued that the occupational exposure of Batman could be estimated by considering the activities of NFL football players (and running backs in particular) and those of professional fighters, such as mixed martial artists. ${ }^{8}$

Concussion is a true occupational hazard in contact sports like hockey and football, which we know have some of the highest concussion incidence rates in sport. ${ }^{4}$ In 2009, the Associated Press published results of an informal survey of 160 NFL players about their experiences with concussion. It included a mix of rookies and veterans across all positions. Half of the players indicated that they had experienced a concussion and just over $1 / 3$ of the players said that the concussion had forced them to miss playing time. Data from the Canadian Football League in 2000 also showed that $\sim 50 \%$ of players indicated that they had experienced a concussion. Just under $20 \%$ of those NFL players interviewed said that they had either not disclosed or trivialised their own concussions and symptoms.

A retrospective survey of martial arts competitions over a 10 year period revealed that about $27 \%$ of matches were stopped because of head impact, 16\% because of 'musculoskeletal stress', 13\% because of neck choke and $12 \%$ due to miscellaneous trauma. ${ }^{15}$ Thus, about $2 / 3$ of the time significant trauma was experienced with an overall injury percentage about 29\%. This is higher than that seen for boxing, which is around $17 \%$. Critically, 1 in 4 matches involved head impact that stopped the competition. Head trauma is a clear concern when fighting is your job.

\section{What is going on with big screen Batman?}

Our analysis confirmed our expectation that Batman has a very high exposure to concussive incidents. Our data are shown in raw events in table 1 and reveal that, taken across all 10 films, Batman was 
exposed to 176 potentially concussive bodily trauma. The all-time low was 1995's Batman Forever starring Val Kilmer (5 events) and the all-time high (43 events) was the first iteration on the big screen shown in the 1943 Batman serialisation starring Lewis G Wilson. The data are also normalised to potentially concussive events per $60 \mathrm{~min}$ of screen time in figure 2. Taken across all 10 films, Batman's average exposure was $\sim 6.5$ events per hour.

This analysis also revealed something unexpected in that Batman's portrayal on the big screen began with a staggeringly high exposure rate of 9.9 potentially concussive incidents per hour back in 1943's Batman serialisation. This rate dropped considerably with the revised 'big screen' debut of Michael Keaton in 1989 ( 4.3) but was recently exceeded in the 2016 Batman V Superman hitting the (so far) all-time high of $\sim 10.3$ incidents. This calculation also includes five events during the physical fight between Batman and Superman that would almost certainly have been fatal for the Caped Crusader.

There are two actors who have played Batman in more than one movieMichael Keaton ${ }^{2}$ and Christian Bale. ${ }^{3}$ Their exposure rates calculated across all movies they were in were $\sim 7.9$ for Bale and $\sim 4.0$ for Keaton. The Batman portrayed by these two actors can be considered to have exposure over longer time frames with possible postinjury vulnerability. Subsequent concussions are usually more severe, with increased symptoms and longer recovery timelines. The return to play protocol from the 2012 Zurich conference describes a graduated return to play that takes at least a week and requires complete symptom resolution at each stage. ${ }^{1}$ In our viewing of the 10 films itemised here, we found no evidence that Batman is following this (or any) return to play protocol. This is particularly worrying since symptoms such as headache, dizziness, cognitive impairment and balance deficits would most likely hinder his fighting skills and make him even more vulnerable to subsequent injury.

\section{Does Batman need to worry about concussion?}

Despite the many potentially concussive exposures to which Batman is shown receiving on a regular basis (both in comics and movies), he is rarely shown having any symptoms of concussion or is even shown as being susceptible to concussion. On the basis of the injury frequency and lack of recovery time we have outlined above, we would expect Batman to experience some serious signs and symptoms, especially impaired cognitive function and balance deficits (we know that these last longer than others). As mentioned earlier, one of the closest examples was found in the 'This one'll kill you Batman' story found in Batman \#260 from January/February 1975. Here he suffers the effects of both getting hit in the head and drinking some coffee that has been drugged with a sedative. As Bruce Wayne, he says to Alfred that he would need "a computer to count the skull knocks I've taken..." Later, in a story from 1998, Alfred says to Bruce Wayne after an incident that "You received a severe concussion in that fall with those idiotic birdwings". These are rare examples and are also rarely found in the movie representations.

\section{Does the Caped Crusader have CTE?}

It is also interesting to speculate whether Bruce Wayne, over the years of his big screen portrayals, has accumulated enough head trauma to show symptoms of CTE. Since prior concussion history makes subsequent concussions more likely with worsening symptoms and longer recovery times, ${ }^{3}$ Batman's repeated exposure to concussive trauma can lead to later issues of cognitive impairment, including dementia, Alzheimer's and Parkinson's diseases, and may be experienced as CTE. ${ }^{16}$ This was first mentioned explicitly in the scientific world in 1928 by Martland $^{17}$ who described a curious neurological syndrome in a long-time boxer and gave rise to the term 'punch drunk'. The terms 'dementia pugilistica' and 'punch drunk' refer to the presentation of impaired motor function and coordination such as that found in alcohol intoxication: slurred speech, problems in maintaining balance, and generally uncoordinated arm and leg movements.

Clearly, repeated blows to the head can lead to persistent effects on movement control and cognition and we know that Batman has been exposed to an excessive

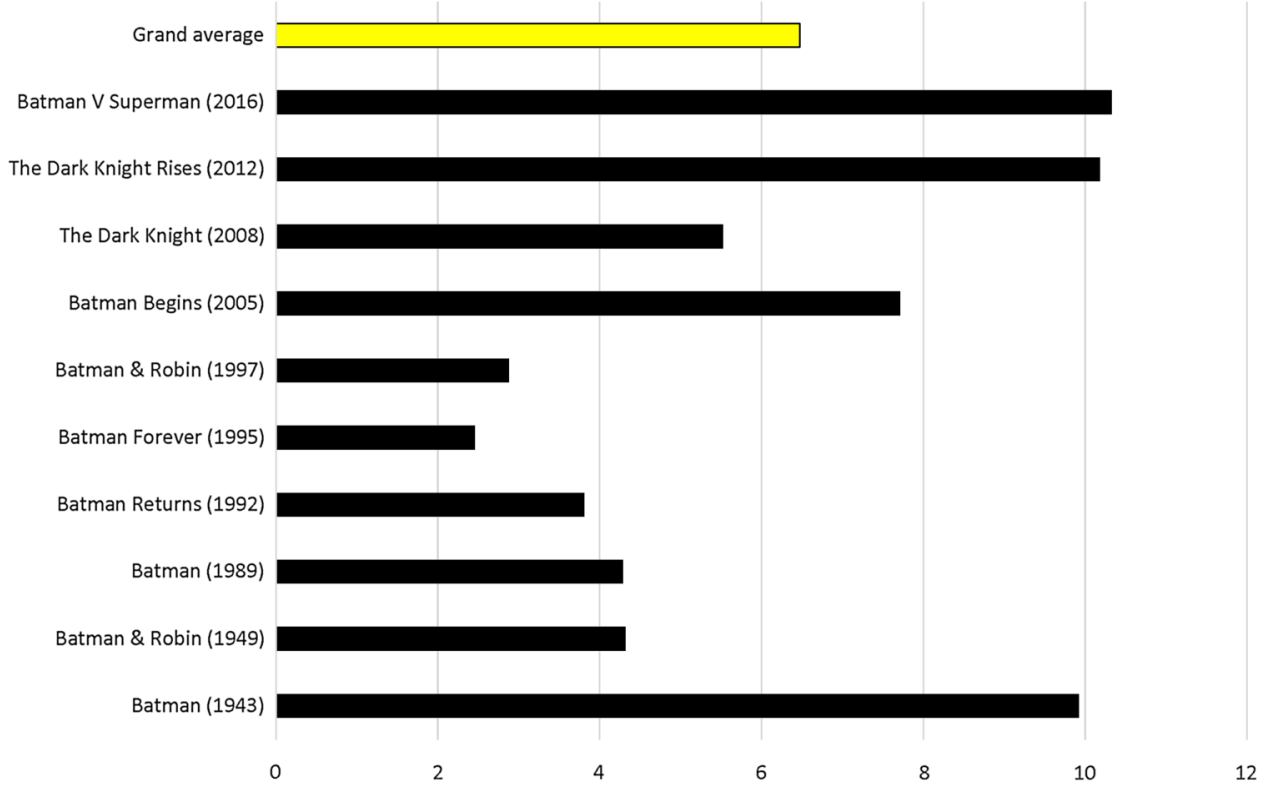

Figure 2 Concussive events to which Batman has been exposed across the 10 big screen representations evaluated in this paper. 
level of such trauma that we would anticipate him to be experiencing these things as well.

Since we would expect large changes in his personality and behaviours if so, we would suggest 'yes'-Batman may indeed have CTE. While in our universe this currently requires postmortem examination, it is possible Batman could convince Superman to assist in an examination, except for the problem of enabling Superman's untimely demise in Dawn of Justice. In any case, CTE would certainly help explain the switch from vigilante using non-lethal force (in 2012's The Dark Knight Rises, Batman says to Catwoman "no guns and no killing" (incidentally, another analysis could look at the recent outlining of sex differences in concussion recovery ${ }^{18}$ ) to the rampant killing machine seen in the 2016 Warner Brothers movie Batman V Superman: Dawn of Justice. There needs to be some rationale for that movie and this is as handy as any.

\section{CONCLUSION}

While it was not part of our direct analysis, it is worth noting that on the big screen Batman has never seen a physician or healthcare provider for possible diagnosis or treatment for concussive head trauma in the movies. Interestingly, in The Dark Knight Rises, Bruce Wayne does see a physician with specialisation in sports medicine and orthopaedics for discussion of his chronic injuries (but not head injury). The advice that he is given is immediately ignored so we might suggest that, after a night of crime fighting trauma, Batman should at least work with Alfred to follow accepted and evidencebased concussion protocols. This would go a long way to determining when (and if) Batman is fit to return to the 'game' the next day. A risk factor for long-term Batman brain health is not just the amount of trauma but the length of time exposed to the trauma. As we detailed here, across his 10 big screen movies spanning 73 years, Batman experienced an enormous 176 concussive events.

Returning to where we began with the concussed football player and the Snickers bar, the quarterback continues to be loopy and woozy while eating the candy bar. The message is that if you are just sitting around and waiting to feel better, you might as well have a Snickers bar. In reality, there are better protocols in place to monitor and treat concussion. Feeding them a Snickers bar is not part of those protocols. We have come a long way in understanding concussion but still have far to go-within the Batcave and beyond.

\section{Twitter Follow E. Paul Zehr at @E_PaulZehr}

Acknowledgements The authors are grateful for the skilful and helpful reading and advice offered by Hilary M Cullen. They acknowledge the topical and tonal inspiration of the BMJ article by Graham Johnson, Indra Guha and Patrick Davies 'Were James Bond's drinks shaken because of alcohol-induced tremor? ${ }^{\prime 19}$

Competing interests None declared.

Provenance and peer review Not commissioned; externally peer reviewed.

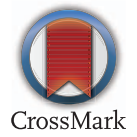

To cite Zehr EP, Wright B. Br I Sports Med 2016;50:1481-1484.

Accepted 8 September 2016

Published Online First 4 October 2016

Br J Sports Med 2016;50:1481-1484.

doi:10.1136/bjsports-2016-096792

\section{REFERENCES}

1 McCrory P, Meeuwisse WH, Aubry M, et al. Consensus statement on concussion in sport: the 4th International Conference on Concussion in Sport held in Zurich, November 2012. Br J Sports Med 2013:47:250-8.

2 Laskas JM. Concussion. New York, New York: Penguin Random House, 2015:288.

3 Mannix R, Meehan lii WP, Pascual-Leone A. Sports-related concussions-media, science and policy. Nat Rev Neurol 2016;12:486-90.
4 Marar M, Mcllvain NM, Fields SK, et al. Epidemiology of concussions among United States high school athletes in 20 sports. Am J Sports Med 2012:40:747-55.

5 Hootman JM, Dick R, Agel J. Epidemiology of collegiate injuries for 15 sports: summary and recommendations for injury prevention initiatives. J Athl Train 2007:42:311-19.

6 Guskiewicz KM, Weaver NL, Padua DA, et al. Epidemiology of concussion in collegiate and high school football players. Am J Sports Med 2000;28:643-50.

7 Fainaru-Wada M, Fainaru S. League of Denial: The NFL, Concussions, and the Battle for Truth. New York, New York: Penguin Random House, 2013:416

8 Zehr EP. Becoming Batman: the possibility of a superhero. Baltimore, MD: Johns Hopkins University Press, 2008.

9 Zehr EP. Inventing iron man: the possibility of a human machine. Baltimore, MD: Johns Hopkins University Press, 2011.

10 Zehr EP. From Claude Bernard to the Batcave and beyond: using Batman as a hook for physiology education. Adv Physiol Educ 2011;35:1-4.

11 Zehr EP. Project superhero. Toronto, Ontario: ECW Press, 2014.

12 Zehr EP. Project superhero: using pop culture to inspire kids' interest in science: scientific American. 2015. http://blogs.scientificamerican.com/guest-blog/ project-superhero-using-pop-culture-to-inspire-kids8217-interest-in-science/

13 Daneshvar DH, Baugh CM, Nowinski CJ, et al. Helmets and mouth guards: the role of personal equipment in preventing sport-related concussions. Clin Sports Med 2011;30:145-63.

14 McGuine TA, Hetzel S, McCrea M, et al. Protective equipment and player characteristics associated with the incidence of sport-related concussion in high school football players: a multifactorial prospective study. Am J Sports Med 2014;42:2470-8.

15 Buse GJ. No holds barred sport fighting: a 10 year review of mixed martial arts competition. $\mathrm{Br}$ J Sports Med 2006:40:169-72.

16 Guskiewicz KM, Marshall SW, Bailes J, et al. Association between recurrent concussion and late-life cognitive impairment in retired professional football players. Neurosurgery 2005; 57:719-26.

17 Martland HS. Punch drunk. J Am Med Assoc 1928;19:1103-7.

18 Broshek DK, Kaushik T, Freeman JR, et al. Sex differences in outcome following sports-related concussion. J Neurosurg 2005;102:856-63.

19 Johnson G, Guha IN, Davies P. Were James Bond's drinks shaken because of alcohol induced tremor? BMJ 2013;347. 